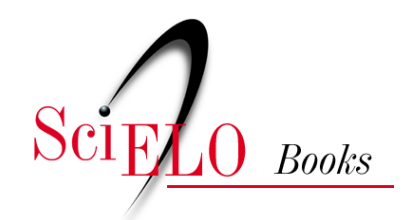

EDUFU

\title{
O teatro na terceira idade
}

\author{
José Luiz Ribeiro
}

RIBEIRO, J.L. O teatro na terceira idade. In: FLORENTINO, A., and TELLES, N., eds. Cartografias do ensino do teatro [online]. Uberlândia: EDUFU, 2008, pp. 133-143. ISBN 978-85-7078-518-3. https://doi.org/10.7476/9788570785183.0014.

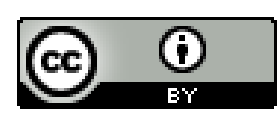

All the contents of this work, except where otherwise noted, is licensed under a Creative Commons Attribution 4.0 International license.

Todo o conteúdo deste trabalho, exceto quando houver ressalva, é publicado sob a licença Creative Commons Atribição 4.0.

Todo el contenido de esta obra, excepto donde se indique lo contrario, está bajo licencia de la licencia $\underline{\text { Creative Commons }}$ $\underline{\text { Reconocimento 4.0. }}$ 


\section{O TEATRO NA TERCEIRA IDADE}

José Luiz Ribeiro

A sociedade contemporânea, fragmentada e especializada, gerou um novo segmento do fazer teatral: o grupo da terceira idade. Aparecendo como uma faixa de consumidor ideal, esse segmento encontrou no teatro um motivo de satisfação. No outono, as folhas caem, porém esta preparação para o inverno é um estágio que, com o passar das estações, apresenta um movimento de eterno retorno. É justamente nesse desprendimento que vamos encontrar, na terceira idade, a oportunidade de um reencontro com desejos íntimos.

Uma larga faixa de opções é estendida ao antigo "ancião". Um verdadeiro supermercado de produtos surge estimulando tanto as ações físicas como os cuidados com a saúde, com a higiene corporal e mental. Turmas especiais de aulas de dança de salão, grupos de viagem, bingos beneficentes, ou não, cursos de atualização e aulas de computação lhes são oferecidos.

Percebendo esse vigor, várias empresas, de olho na potencialidade econômica dessa faixa de mercado, começam a contratar atores idosos para criar uma imagem simpática de velhinhos incríveis que anunciam viagens, esportes radicais, aconselham planos de saúde maravilhosos e uma infinidade de produtos dirigidos ao bem-estar do idoso.

Dentro dessa gama de ofertas, o teatro se apresenta como uma atividade saudável que amplia a potencialidade da qualidade de vida, restaura o fazer da cidadania e alimenta o campo emocional com atividades físicas, ações emotivas, desenvolvimento da personalidade e exercício da memória. Assim, o preparo do profissional que se dedica ao trabalho com a terceira idade necessita de juntar conhecimentos cênicos, um certo lastro de saberes e uma prática de valores humanos.

\section{Por que fazer teatro na terceira idade?}

A cada atividade que se realiza buscando o fazer teatral, é necessário um mapeamento do público-alvo. Não apenas levando em conta a idade, mas o nível socioeconômico, a procedência regional e os hábitos de entretenimento. O lastro memorial é de grande importância para se definir objetos e objetivos.

O teatro para a faixa de terceira idade tem uma força muito grande no imaginário da memória coletiva. A força do rádio e o mito de atores que percorriam 
o interior em apresentações mambembes integram-se à cultura popular. Os melodramas apresentados como complemento de funções circenses, acrescentam-se também a esse patrimônio.

No interior, companhias itinerantes levavam atores como Procópio Ferreira, Dulcina, Henriette Morineau, Jaime Costa, Rodolfo Mayer, dentre outros, para apresentações que marcavam o evento dos jovens de outrora. O teatro foi, para essa geração, um encontro com a emoção, com o riso e com histórias que caracterizavam ou se acrescentavam ao universo cultural local do brasileiro.

Existe, ainda, um resquício do teatro escolar. A glória de um talento abortado pela vida fica reprimida como um sonho irrealizado. A recuperação de momentos felizes são os principais instrumentos que proporcionam, aos grupos de terceira idade, o encontro de motivações para buscar no teatro um momento de realização pessoal.

Muitos dos que procuram um grupo de apoio encontram aí uma forma de sociabilização que supre carências afetivas, devolve a segurança perdida e possibilita a criação de novo círculo de amizades. Recuperando a voz, abafada pelo cotidiano de tarefas domésticas ou burocráticas desenvolvidas mecanicamente, eles buscam, na atividade teatral, uma forma de rever conceitos e assumir novas atitudes. A magia, o jogo e o poder de transformação são caminhos a percorrer.

\section{A identidade do grupo}

O teatro é uma arte de contágio. Realizando-se a partir da inclusão dos atores num jogo em que a platéia atua como parceira, necessita de um preparo de inclusão social para atingir seus objetivos. O primeiro passo é o da identificação dos componentes de um grupo. Esse princípio básico, que caracteriza qualquer metodologia do fazer teatral, é necessário em grupos diversos, mas exige um cuidado especial quando se trata de um grupo de terceira idade.

Estabelecer parcerias é um bom passo para sua formação, e isso vai ser feito através da fixação das regras do jogo. A construção do ator ativa o afloramento das alteridades. Um grupo de terceira idade possui muitas certezas e opiniões solidificadas, e para eliminar os conflitos deve-se aparar as arestas, evitar desentendimentos ou incentivar a evasão de individualismos aflorados durante essa nova experiência de resgate identitário. $\mathrm{O}$ encontro de motivações comuns estabelece os objetivos para o mapeamento do grupo.

O primeiro encontro é cerimonioso. As apresentações tornam-se necessárias para enfrentar os dois instintos básicos: o de platéia e o de representação. O jogo tem início com um seminário de revelações pessoais. Cada participante, mostrando-se, torna-se um ator de si mesmo, vivendo uma personalidade delineada pelos interditos e cuidadosamente dosada.

Nesse primeiro encontro é necessário perceber a divisão dos caracteres, das posturas e da forma de exposição. É comum que pessoas de terceira idade, extremamente tímidas, procurem fazer parte de um grupo de teatro como forma de vencer esse traço incômodo de personalidade. O teatro é uma forma de dar voz a esses incluídos. Mas o embate com outros membros, extrovertidos e falantes, gera o primeiro estremecimento, mas também a fresta do entendimento. Para se 
equilibrar através dessas primeiras revelações, passamos para o entrosamento das identidades variadas.

\section{Jogos de outono}

O teatro é um ato de comunicação estética e natureza lúdica. $\mathrm{O}$ jogo busca libertar o homem de suas tensões cotidianas e isso acontece na representação. $O$ primeiro estágio para conseguir a integração do grupo é deixar claro que a coletividade solidária é a principal regra desse jogo. Não é difícil para uma pessoa madura percorrer caminhos de volta através da rememoração. Para vencer a inibição dos primeiros instantes, gerada pela postura de observador crítico, muitas vezes tímido, podemos recorrer às apresentações protocolares.

O primeiro jogo se organiza quando o grupo se despersonaliza para se contar individualmente. Pedimos aos participantes que falem de si como se fosse de um outro. Conta-se, então, uma história na terceira pessoa. Ao eliminar o eu, transformado em ele ou ela, inicia-se a narrativa de fatos cotidianos.

A edição de uma vida, buscando fatos marcantes a partir dos insignificantes, permite uma diagnose de máscaras sociais. Rever a vida para o idoso é como percorrer o mito de Fausto, um julgamento de perdas e danos. É recontar fatos encadeados de forma emocionada, despertando empatias, risos e lágrimas.

Os primeiros encontros decantam as personalidades e manifestam comportamentos. O grande impacto está, agora, na organização de uma comunidade dotada de massa crítica. O jogo teatral terá grande importância para formar essa comunidade, criando objetivos que serão alcançados e dificuldades que serão vencidas.

A cada passo dessas apresentações distanciadas encontramos a quebra do gelo inicial. Revelações sempre geram interesse para uma comunidade que pretende tornar-se um grupo teatral. Contar e recontar é uma forma de ritualizar bons e maus momentos.

\section{Riso com muito siso}

Um grupo que se reúne para fazer teatro na terceira idade busca o prazer. Mas a alegria de participar de um espetáculo inclui também um investimento no método. É importante que se trace uma linha de objetivos a serem alcançados: que tipo de espetáculo que se quer produzir, qual o trabalho a ser desenvolvido e a potencialidade de crescimento do elenco.

A ética será o principal caminho a percorrer. A disciplina dos encontros deve ser mantida ferreamente e cada participante conscientizado de que um grupo que se forma para fazer teatro deve ter plena consciência de que, como nos diz Pirandello, em Seis personagens à procura de um autor, "o palco é um lugar onde se brinca a sério". As normas de comportamento precisam ter linhas preestabelecidas quanto à pontualidade e a assiduidade de cada participante.

Um dos grandes empecilhos para a atividade da terceira idade está no processo de vitimização. Como nos afirma a sabedoria popular, "O diabo é sábio porque é velho" e por isso não podemos nos esquecer de que existem alguns comporta-

\footnotetext{
${ }^{1}$ PIRANDELLO, Luigi. Seis personagens à procura de um autor. São Paulo: Abril, 1977. p. 134.
} 
mentos que escamoteiam a verdade diante do grupo. O idoso, por tradição social, é encarregado pela família de cumprir tarefas "por amor": ficar com os netos ou buscá-los na escola; somando-se a isso ainda tem a série interminável de exames e consultas médicas nos horários dos ensaios.

Há que se exigir o "arrebatamento dos jogadores para se chegar à imaginação criadora" 2 . Ao integrar um grupo teatral, deve-se ter um compromisso com o "sacro ofício" e doar-se de forma integral ao empreendimento: respeitar o ingresso no tempo mítico do teatro de forma ortodoxa. $O$ jogo teatral tem suas regras e, para que aconteça, é preciso que sejam respeitadas. Cada participante será seu fiscal e deverá zelar para que a ordem reine soberana em busca da concretude dos objetivos.

\section{Movimentos dialógicos}

As atividades tribais incluem sempre um rito. Um grupo deve, aos poucos, criar nos ritos o fator de integração. Para isso é importante notar que cada indivíduo traz dentro de si um campo de experiências vividas. Essa formação envolve uma filosofia vivencial, cadenciada pela sociedade e pelo campo de aspiração que dimensiona carências e sonhos. Diante desses fatores, um grupo de terceira idade busca acertar as contas com a vida. A busca do lucro, depois de tantas pequenas perdas, é um instrumento de sobrevivência. O conflito social, que alijou o velho do poder familiar, elegeu novas estratégias para recomposição do estar no mundo de um grupo que se nega à imobilidade dos condenados à morte.

Assim, detectar os campos de experiência comum a cada participante importa em criar um lastro não só para a vivência teatral, mas também para a preservação identitária das nações, possibilitando a presença da diversidade em convivência com o global. Ao estabelecer tópicos para a discussão, pode-se criar um vasto arsenal de reminiscências. O encadeamento destas memórias vai despertar momentos de recuo temporal em que as lembranças atuam na esfera da memória afetiva exorcizando antigos recalques.

Buscar respostas em sentimentos vividos vai permitir o desenvolvimento da atuação dramática acordando a memória de emoção tão praticada pela herança do Método Stanislavski. Reviver é viver de forma crítica, assim como rever é ver com outros olhos. Nas raízes da espontaneidade vamos encontrar um processo de ações e reações que motivam o jogo dramático, conferindo certa "verdade cênica" ao trabalho. Esse modelo de representação, que busca convencer a si mesmo de suas potencialidades, é a primeira resposta a ser procurada para uma atuação segura.

\section{As ações corpóreas}

A fisiologia de um grupo de idosos é variável. Qualquer um que pretenda fazer parte da atividade teatral é movido por um vigor adolescente. Ao encontrar identificação, as relações tornam-se afetivas. Rapidamente passamos a deixar de lado o protocolo para, através de atividades dirigidas, eliminarmos conceitos e preconceitos.

2 HUIZINGA, Johan. Homo Ludens: o jogo como elemento da cultura. São Paulo: Perspectiva,1971. p. 20. 
Recorrer aos folguedos populares é um bom princípio. Cirandas, cantigas de trabalho ou modinhas são importantes por dois motivos: o primeiro é o reencontro com a infância, com as lembranças de brincadeiras infantis; o segundo é a formação de um repertório de atos vividos em passado não muito próximo, mas que a sabedoria da natureza se encarrega de privilegiar na memória.

As rodas de energia são um bom começo para vencer a barreira do contato físico. Iniciando com apertos de mão e terminando com abraços calorosos, o grupo começa por se tocar, vencendo barreiras culturais e étnicas. A dinâmica do corpo é importante para recuperar eixos e posturas.

O uso de música, aliado a exercícios respiratórios, pode permitir, nos jogos de leveza, um momento de descontração com balões que flutuam a um suave toque. A busca do movimento e a harmonização do gesto podem ser conseguidas e utilizadas como instrumentos para os jogos de integração.

O lúdico deve ser adotado. Músicas folclóricas ou de raízes populares são, então, utilizadas como marcação rítmica em que as palmas criam a relação grupal, através da mecânica rítmica. Dessas manifestações surgem risos pelos erros cometidos e estaremos preparados para o próximo passo: os exercícios de alongamento, deslocamentos com a utilização de relaxamento e tensão. Cantar e se movimentar é uma etapa importante para elaborar a planilha de atividades para a terceira idade.

\section{Passos e compassos}

A idade faz com que o ser humano perca, aos poucos, a intensidade do exercício de seus sentidos. O treinamento da atenção é um princípio básico para a recuperação dessas atividades. E como motivação, o teatro fornece muitos impulsos para que as pessoas recuperem, de forma lúdica, qualidades para uma boa atuação: saber ouvir para melhor responder.

A dança é o primeiro passo do treinamento. Recordar o tempo em que dançar reproduzia normas comportamentais entre damas e cavaleiros, em que a dança de salão era organizada em direção às relações prazerosas do lazer, sem as exigências performáticas imprimidas pelos modernos cursos do gênero, onde os pares se enlaçam com a matemática dos volteios exibicionistas, é uma tarefa divertida.

Ao se tocar na dança, ao acertar os passos, temos o início de uma atividade corporal que se automatiza impulsionada pelo ritmo. A atenção passa a fazer parte dos exercícios, criando espírito crítico diante de acertos e erros. A preocupação com os passos e a execução das propostas consegue um aprimoramento para futuras execuções de marcas coreográficas.

Das lembranças dos antigos bailes, passamos a exercícios mais elaborados com jogos dramáticos incentivando a atenção rumo à execução de coreografias grupais. Passos coreografados, ou criados pelo grupo, podem sofrer alterações e encadeamentos gerando formas diferentes de treinamento.

Temos, agora, um grupo que canta, dança e executa marcas coreográficas. Cada acerto é gratificado com a alegria de ter vencido mais uma etapa e se cada erro é mostrado como uma nova dificuldade a ser vencida, os acertos são vitórias comemoradas e que imprimem segurança a cada participante e afirmação no grupo. A integração se dá através da dinâmica corporal. 


\section{Do cantar ao falar}

A intercessão do teatro com literatura confere ao texto uma importância documental. Se o texto é a semente do espetáculo, sua interpretação é a forma de torná-lo vivo e próximo ao tempo em que vivemos. Dizer um texto confere ao intérprete uma responsabilidade que necessita de treinamento e abertura dos poros sensíveis.

Para o ator de terceira idade o contato com a literatura se fez, muitas vezes, nos bancos da escola. Talvez essa seja uma das grandes dificuldades para quem se propõe a fazer teatro na terceira idade. É preciso demonstrar, em primeiro lugar, que falar de cor é falar de coração. O rumor da língua envolve uma musicalidade conferida pela retórica.

Durante muito tempo, a declamação possuía um maneirismo, como quando o teatro brasileiro, relembrando Bandeira, de "Recife", "macaqueava a sintaxe lusíada”. Para o ator de terceira idade a declamação com trinados na voz ainda é o modelo. A primeira dificuldade é aproximar este aspirante a ator de um discurso coloquial contemporâneo. Tornar a fala natural, mas sensível e colorida, torna-se outro desafio a vencer.

A invenção da dimensão simbólica e a musicalidade da entonação tornam-se um bom mote para o exercício nas leituras de mesa, com entendimento prévio das intenções das falas. Dependendo do nível de escolaridade do grupo, esta fase deve merecer cuidado especial. Partir da poesia lírica, interpretar crônicas, passar por contos e textos dialogados são itinerários a percorrer.

É necessário criar uma noção do ritmo da frase em prosa. Perceber a pontuação como sinalização de intenções, as pausas respiratórias, buscar intenções nas palavras é saber usar sua força. A musicalidade da fala permite traçar imagens na mente dos espectadores. Entender, falar e convencer são passos para que um ator viabilize a sua interpretação. Libertar-se da leitura mecânica, fixa e sem colorido é a meta a atingir.

\section{O drama do esquecimento}

A questão da memorização talvez seja o maior pesadelo para um grupo de terceira idade que começa a fazer teatro. A preocupação com palavras deve ser, de imediato, substituída pela lógica de ação, através do exercício criativo de sucessão de imagens. A dispersão da atenção, gerada pela preocupação em reter automaticamente o texto, deve ser combatida.

O homem pensa por imagens. Associá-las é um bom exercício para a memorização das falas. Mas o mais importante, quando se trata de um texto dialogado, é saber ouvir como personagem. Dividir cada réplica de maneira minuciosa e proceder ao estudo das intenções da personagem, aliado à diagnose do papel, poderá fazer nascer grandes discussões sobre o procedimento de cada papel conforme a configuração da personalidade a ser representada.

A fixação de palavras-chave que determinam a ação propositiva de cada fala pode resultar em uma reelaboração textual. A palavra torna-se, então, marca para o treinamento mnemônico. A absorção da qualificação como primeiridade do signo poderá fornecer o desenvolvimento orgânico da interpretação. Esse procedimento vai eliminar a fala dura, sem colorido e artificial. 
Certamente o idioleto do ator é um fator de predominância quando tratamos de um grupo que pretende montar um espetáculo. As características pessoais devem ser aproveitadas no momento da distribuição dos papéis, mas um bom exercício de aprimoramento é também a imitação, pelos membros do elenco, dos idioletos grupais mais marcantes. Nesse jogo de divertimento, cria-se o distanciamento que, através do riso, possibilita a improvisação. A resposta rápida e o estado de prontidão poderão levar um bom rendimento ao desempenho dos atores e vencer problemas da memória.

\section{$\mathrm{O}$ ator médium}

A criação da personagem no grupo de terceira idade passa por um processo de transferência de vivências. Um segundo momento é o de alertá-lo sobre a diferença entre palco e vida. Muitas vezes a escalação do papel pode ser prejudicada pelo narcisismo, que será vencido na medida em que nasça a consciência do fazer teatral.

$\mathrm{Um}$ ator re-apresenta o mundo. Em alguns casos é muito difícil convencer a um iniciante de terceira idade de que o papel que lhe foi atribuído não está ligado a sua vida pessoal. O convencimento de que teatro é um jogo é o primeiro estágio para vencer conflitos que perpassam os mais diversos grupos: o triunfo da vaidade.

O conflito entre o real e o imaginário percorre a história do teatro desde que Théspis, o primeiro ator, foi severamente advertido por Sólon. Para o ator de terceira idade, numa experiência amadora, o objetivo pessoal pode superar a humildade necessária ao aprendizado e aprimoramento. Existe um elemento que perturba a ordem espetacular: a existência da competição originada dentro do próprio grupo.

Entretanto, a competição natural, gerada pela vontade de participar, tem que ser colocada como um princípio de afirmação da alteridade. Para que isso aconteça é preciso fortalecer o sentimento de grupo e isso se faz diante do resultado final. A cumplicidade é um fator primordial a ser desenvolvido num grupo que se propõe a fazer teatro.

Viver a personagem não é ser a personagem. A consciência de um ator em ser médium sem, no entanto, perder o senso de representação nasce da utilização de saber ouvir para melhor responder. Essa sintonia só se dá quando ele amadurece sua criação. Esse passo é primordial num grupo maduro que procura ter voz ativa numa atividade artística. Ouvir para responder com lógica a cada situação é fazer aflorar a denúncia cidadã na sensibilidade e canalizar a expressão da atuação.

\section{A relação espetacular}

A rede expressiva da polifonia teatral é um fato. Conhecer as etapas da estrutura de produção de um espetáculo é respeitar o todo da criação artística e não abastardar qualquer fase de composição da mensagem espetacular. $\mathrm{O}$ respeito ao fazer teatral deve ser despertado no grupo para assegurar um bom produto final.

O mecanismo cênico move-se na instância grupal. A superposição das individualidades sobre o objetivo do grupo pode gerar desgastes relacionais que têm que ser resolvidos. Para isso, a clareza de objetivos, a solidariedade do jogador e a generosidade da doação são propostas a serem exercitadas a cada dia, num compromisso constante com a renovação dos valores da humanidade. 
Uma casa dividida, não se sustenta. Assim, cada ponto de apoio deverá ser contemplado, e o reconhecimento da importância de cada detalhe fazer parte do projeto comum. Isso vai possibilitar ao ator melhor desempenho no palco e no grupo. A percepção de que o cenário, o figurino, a luz, a música e a coreografia estão a serviço de uma causa comum amplia a qualificação do ator e sua consciência do fenômeno teatral.

Ao reconhecer o universo espetacular e identificar sua importância, o ator saberá entender que figurino é mais do que uma fantasia carnavalesca, que a cor utilizada nem sempre é a de sua preferência ou a que mais lhe favoreça esteticamente mas, com certeza, é a mais apropriada ao espetáculo. Aumentando o conhecimento, eliminamos a fogueira das vaidades.

O prazer da representação está no ato da transformação. As representações revestem-se de maior autenticidade quando o ator se liberta do real para atingir o universo dramático. O distanciamento, através do cômico, substitui a atração narcisista pela epifania do ator suporte e essência da criação dramática.

\section{Ritual de troca}

Depois do treino, chega a hora do jogo. A criação do espetáculo culmina no momento mágico da apresentação. Dividir com um público especial o seu trabalho é para este ator, também especial, que procura o teatro na terceira idade, um momento de afirmação social e familiar. Ao vencer a barreira que parecia instransponível, ao eliminar medos e temores chega à vitória final.

Se, como nos diz Mc Luhan, "a função da arte na sociedade tribal não é orientar a população para a novidade, mas fundi-la com o cosmo", a interligação entre o palco e a platéia cria um rito de celebração no qual se penetra como numa experiência catártica. Não existe nesta celebração lugar para a ratio, apenas o pathos triunfa, através da comunhão dos pertencentes.

Observa-se, então, o fenômeno da transfiguração, quando filhos, esposos e esposas descobrem um artista em suas famílias. O público amigável deixa o espaço da consciência crítica para ingressar na comunhão dionisíaca na qual, como nos fala Stanislavski:

[...] muitos sentimentos incomunicáveis superconscientes, invisíveis, que nem o equipamento físico mais perfeito pode transmitir. São passados diretamente de alma para alma. As pessoas comungam umas com as outras por meio de correntes interiores invisíveis, radiações de seu espírito, compulsão de sua vontade $[\ldots]^{4}$.

A grande caracterização do espetáculo de grupos de terceira idade está no seu público. Esse espectador tem como ponto referencial os laços afetivos. É um público que não vai apenas assistir a uma peça teatral, vai reverenciar um ente querido.

${ }^{3}$ McLUHAN, Marshall; WATSON, Wilfred. Do clichê ao arquétipo. Rio de Janeiro: Record, 1973. p. 208.

4 STANISLAVSKI, Constantin. A preparação do ator. Rio de Janeiro: Civilização Brasileira, 1964. p. 102. 
Tudo isso gera uma corrente de energia positiva através da atenção comprometida. A espera ansiosa pela entrada do representante familiar na apresentação e os aplausos encantados a cada cena, marcam o tempo mítico da festa que se instaura soberano na casa de espetáculos.

\section{Colhendo os frutos}

Eis o momento de listar os benefícios para o idoso que participa de um grupo teatral. O primeiro deles é a restauração de envolvimento num rito social dentro de uma cultura cada vez mais tecnológica e distanciadora do contato humano. Quanto maior a tecnologia, maior a necessidade de magia. E o teatro fornece o círculo mágico onde o ser se reestrutura numa ligação cosmogônica.

A relação social gera o respeito pela alteridade e nessa contrapartida o autoconhecimento passa a ser um ponto de desbloqueamento de preconceitos. A visão de mundo, sem sentimento de autopiedade, proporciona maior segurança para enfrentar a realidade. Desenvolve-se, a partir de então, a consciência cidadã plena de reivindicações.

O aprimoramento do discurso permite o uso de uma retórica segura que dialoga e defende pontos de vista; a saúde corporal é beneficiada pelos procedimentos de aquecimento, postura e reavaliação de potencialidades; a saúde mental desenvolve-se com treinamentos de atenção e memorização; a sensibilidade amplia-se com uma visão mais acurada do mundo sensorial. A realidade passa a ser vista de maneira mais racional: aprendem-se estratégias comunicativas que permitem abordagens de novas políticas sociais, culturais e educacionais.

E, por fim, encontramos um processo de reabastecimento da sensibilidade e da organização psicológica diante do mundo. Como num incêndio na floresta, em que os animais fogem juntos em busca de preservação, os idosos se juntam num mundo juvenilizado pela sociedade de consumo, mas mantêm sua identidade através valores preservados, mas renovados. A decantação do cotidiano reorganiza a tribo e a afirmação de identidade adquirida pelos atores da terceira idade é prova da existência daqueles que se recusam a capitular e se reinventam com nova máscara.

\section{Conclusão: a arte de empinar pipas}

O profissional que se destinar a desenvolver um trabalho teatral com um grupo de terceira idade deverá, antes de tudo, saber empinar pipas. Saber medir a força do vento, puxar a linha em pequenos arrancos e liberar, com segurança, para que a pipa voe mais alto.

Um grupo de terceira idade, ao contrário de um grupo jovem, organiza-se com um passado e um campo de aspirações próprio. Ao buscar uma atividade artística em que o suporte é o homem, o aspirante a ator tem desejos recônditos de reencontrar um sonho interditado, viver uma experiência juvenil ou rumar em direção a um mundo mágico desconhecido que o atrai.

Exige-se do condutor desta tribo uma grande dose de paciência, carisma e senso analítico capaz de criar novas estratégias diante de novas propostas. A carência que envolve o idoso o faz buscar um ouvinte atento e alguém que lhe dedique atenção e afetividade. Porém, é importante perceber que o avanço da humanidade se 
faz diante de novos desafios. Assim, seria interessante notar que só o temor constrói. Ele modifica o ser humano, cria novas estratégias e engendra novas soluções para velhos problemas.

Existe em grupos de idosos um comportamento juvenil. Há necessidade do riso, da festa e, em especial, a carência de comemorações de datas festivas. As celebrações rituais com pequenas lembranças, atividades de entretenimento, demonstraçóes de afeto fazem parte de qualquer grupo humano, mas em se tratando de um grupo que faz teatro isso é marcante.

O teatro é um instrumento de transformação social que permite, a quem o pratica, uma revisão constante de sua natureza e uma visão renovadora do mundo. Para quem se prepara para viver grandes emoções, ainda que tardiamente, o teatro é o portal do prazer, da festa e da alegria. 


\section{REFERÊNCIAS}

HUIZINGA, Johan. Homo Ludens: o jogo como elemento da cultura. São Paulo: Perspectiva, 1971.

McLUHAN, Marshall; WATSON, Wilfred. Do clichê ao arquétipo. Rio de Janeiro: Record, 1973.

PIRANDELLO, Luigi. Seis personagens à procura de um autor. São Paulo: Abril, 1977.

SOEIRO, Alfredo Correia. O instinto de platéia. Porto: Edições Afrontamento, 1990.

STANISLAVSKI, Constantin. A preparação do ator. Rio de Janeiro: Civilização Brasileira, 1964. 